\title{
Mechanisms Underlying Functional Changes in the Primary Motor Cortex Ipsilateral to an Active Hand
}

\author{
Monica A. Perez and Leonardo G. Cohen \\ Human Cortical Physiology Section and Stroke Neurorehabilitation Clinic, National Institute of Neurological Disorders and Stroke, National Institutes of \\ Health, Bethesda, Maryland 20892
}

\begin{abstract}
Performance of a unimanual hand motor task results in functional changes in both primary motor cortices ( $M 1_{\text {ipsilateral }}$ and $\left.\mathrm{M} 1_{\text {contralateral }}\right)$. The neuronal mechanisms controlling the corticospinal output originated in $\mathrm{M}_{\text {ipsilateral }}$ and the resting hand during a unimanual task remain unclear. Here, we assessed functional changes within $\mathrm{M}_{\text {ipsilateral }}$ and in interhemispheric inhibition (IHI) associated with parametric increases in unimanual force. We measured motor-evoked potential (MEP) recruitment curves (RCs) and shortinterval intracortical inhibition (SICI) in $\mathrm{M}_{\text {ipsilateral }}$, IHI from $\mathrm{M} 1_{\text {contralateral }}$ to $\mathrm{M}_{\text {ipsilateral }}$, and the influence of IHI over SICI using transcranial magnetic stimulation at rest and during 10,30, and 70\% of maximal right wrist flexion force. EMG from the left resting flexor carpi radialis (FCR) muscle was comparable across conditions. Left FCR MEP RCs increased, and SICI decreased with increasing right wrist force. Activity-dependent (rest and 10, 30, and 70\%) left FCR maximal MEP size correlated with absolute changes in SICI. IHI decreased with increasing force at matched conditioned MEP amplitudes. IHI and SICI were inversely correlated at increasing forces. In the presence of IHI, SICI decreased at rest and $70 \%$ force. In summary, we found activity-dependent changes in (1) SICI in M1 ${ }_{\text {ipsilateral }}$ (2) IHI from $\mathrm{M} 1_{\text {contralateral }}$ to $\mathrm{M} 1_{\text {ipsilateral }}$, and (3) the influence of IHI over SICI in the left resting hand during force generation by the right hand. Our findings indicate that interactions between GABAergic intracortical circuits mediating SICI and interhemispheric glutamatergic projections between M1s contribute to control activity-dependent changes in corticospinal output to a resting hand during force generation by the opposite hand.
\end{abstract}

Key words: primary motor cortex; interhemispheric inhibition; transcallosal pathways; intracortical inhibition; transcranial magnetic stimulation; force

\section{Introduction}

The primary motor cortex contralateral $\left(\mathrm{M} 1_{\text {contralateral }}\right)$ to a moving hand undergoes activity-dependent adaptations (Evarts, 1968; Lemon et al., 1986; Maier et al., 1993; Ashe, 1997). Functional magnetic resonance imaging (fMRI) studies have shown that blood oxygenation level-dependent signal activity in $\mathrm{M} 1_{\text {contralateral }}$ relates to the type and magnitude of the motor action (Dettmers et al., 1995; Dai et al., 2001), as does the amplitude of motor-evoked potentials (MEPs) elicited by transcranial magnetic stimulation (TMS) (Flament et al., 1993; Hasegawa et al., 2001; Ni et al., 2006).

Task-related adaptations have also been reported in the M1 ipsilateral $\left(\mathrm{M}_{\text {ipsilateral }}\right)$ to an active arm. In monkeys, activity in neurons within $\mathrm{M} 1_{\text {ipsilateral }}$ depends on the type of upper-limb movement (Tanji et al., 1988; Cisek et al., 2003). fMRI (Dettmers et al., 1995; Thickbroom et al., 1998; Dai et al., 2001; van Duinen et al., 2008) and TMS (Hess et al., 1986; Stedman et al., 1998;

\footnotetext{
Received Jan. 9, 2008; revised April 20, 2008; accepted April 20, 2008.

This work was supported in part by the Intramural Research Program of the National Institutes of HealthNational Institute of Neurological Disorders and Stroke.

Correspondence should be addressed to Dr. Leonardo G. Cohen, Human Cortical Physiology Section, National Institute of Neurological Disorders and Stroke, National Institutes of Health, 10 Center Drive, Bethesda, MD 208921430. E-mail: cohen!@ninds.nih.gov.

DOI:10.1523/JNEUROSCI.0093-08.2008

Copyright $\odot 2008$ Society for Neuroscience $\quad$ 0270-6474/08/285631-10\$15.00/0
}

Tinazzi and Zanette, 1998; Muellbacher et al., 2000; Hortobagyi et al., 2003) studies in humans revealed functional changes in $\mathrm{M} 1_{\text {ipsilateral }}$ during parametric increases in unimanual force. Additionally, motor learning studies have demonstrated the involvement of $\mathrm{M}_{\text {ipsilateral }}$ during acquisition of unimanual motor skills (Chen et al., 1997; Davare et al., 2007; Duque et al., 2007; Perez et al., 2007). Although increasing evidence points to the involvement of $\mathrm{M} 1_{\text {ipsilateral }}$ during performance of a unimanual motor task, the neuronal mechanisms controlling the corticospinal output originated in the $\mathrm{M} 1_{\text {ipsilateral }}$ and the resting hand remain unclear. Gaining insight into these mechanisms may contribute to a better understanding of how unimanual and bimanual movements are controlled (Carson, 2005).

Activity in $M 1_{\text {ipsilateral }}$ may be influenced by input from the opposite $\mathrm{M} 1_{\text {contralateral }}$ (Carson, 2005). In humans, interhemispheric inhibitory interactions between M1s can be measured using a paired-pulse TMS technique [interhemispheric inhibition (IHI)] (Ferbert et al., 1992). IHI is absent in patients with callosal lesions or agenesis of the corpus callosum, suggesting that they involve transcallosal pathways (Rothwell et al., 1991; Meyer et al., 1995). Transcallosal pathways between motor cortices and intracortical inhibitory circuits contribute to control the corticospinal output from the M1 (Avanzino et al., 2007; Lee et al., 2007). Therefore, we hypothesized that their interactions may contribute to control the corticopinal output from $\mathrm{M1}_{\text {ipsilateral }}$ in an activity-dependent manner. 
The purpose of the present study was to gain insight into the mechanisms controlling the corticospinal output to a resting hand (originated in $\mathrm{Ml}_{\text {ipsilateral }}$ ) during performance of a force generation by the contralateral hand. We measured activitydependent changes in motor cortical excitability [MEP recruitment curves (RCs)], short-interval intracortical inhibition (SICI) (Kujirai et al., 1993), IHI (Ferbert et al., 1992), and the influence of IHI over SICI (Daskalakis et al., 2002) as a function of parametric changes in unimanual wrist force flexion. We found that SICI in $M 1_{\text {ipsilateral }}$ and IHI from $M 1_{\text {contralateral }}$ to $M 1_{\text {ipsilateral }}$ as well as their interactions differed at different force levels, indicating that interhemispheric connections between M1s provide one possible pathway by which $M 1_{\text {ipsilateral }}$ is facilitated, whereas modulation of intracortical inhibition may provide a mechanism for the facilitation.

\section{Materials and Methods}

Subjects. Ten right-handed healthy volunteers (five women and five men) with an average age of $27.5 \pm 4.2$ years participated in the study. All subjects gave their informed consent to the experimental procedure, which was approved by the National Institute of Neurological Disorders and Stroke (NINDS) ethics committee. The study was performed in accordance with the Declaration of Helsinki. All subjects participated in three to four testing sessions separated by at least $2 \mathrm{~d}$ in the Human Cortical Physiology Section laboratory at NINDS, National Institutes of Health. On each session, subjects performed 10, 30, and 70\% of their maximal right wrist flexion force in a randomized order with the right arm while the left arm remained at rest. Measurements of motor cortical function were acquired at the different force levels and at rest (see below, TMS measurements).

Motor task. Subjects were seated in an armchair with both arms flexed at the elbow by $90^{\circ}$ and the wrist in a neutral position. The right arm was attached to a custom six-axis load cell (35-E15A; JR3), which measures the forces exerted by the subject (Fig. 1A). Custom software was written to acquire signals from the load cell and to display visual feedback corresponding to rest and 10,30, and 70\% of each subject maximal right wrist flexion force in real time (Matlab R14SP3; Mathworks). Subjects were instructed to respond to the GO signal (target signal) presented on a computer monitor by moving a cursor to a target box. Figure $1 B$ illustrates the location of the target box showing that at $10 \%$ of force there is a small distance between the target signal and target box compared with $70 \%$ of force. Subjects had to maintain the cursor in the target box for 3-5 $s$ by performing a right wrist flexion isometric contraction. The instruction for the subject was "When you see the GO signal, bend the right wrist and completely relax the left arm." The maximal right wrist flexion force was measured three times at the beginning of each session, and measurements were averaged. Electrophysiological measurements were taken at rest and during 10,30, and 70\% of maximal right wrist flexion force. At the time the GO signal appeared on the computer screen, a trigger pulse was sent to a software program (Signal), which in turn triggered the TMS. Each TMS pulse was applied during the right flexor carpi radialis (FCR) voluntary muscle burst in all force trials. During testing, the left arm was immobilized by a custom brace to ensure that the same testing position was maintained in all experimental sessions. The left FCR electromyogram (EMG) was displayed as a continuous line on an oscilloscope during right wrist voluntary contraction, and feedback was constantly shown to participants and experimenters. In addition, verbal feedback was provided to the subjects to assure that the left FCR remained at rest at all times. In individual traces, EMG activity on the left FCR was analyzed 500 $\mathrm{ms}$ before the stimulus artifact. Trials in which left FCR activity exceeded the background noise level of $25 \mu \mathrm{V}$ were excluded from additional analysis (Muellbacher et al., 2000). In $\sim 11.2 \%$ of trials, subjects were unable to relax the left FCR completely; this is consistent with a previous report (Hortobagyi et al., 2003).

Electromyographic recordings. Surface electrodes were positioned bilaterally on the skin overlying the FCR muscles in a bipolar montage (interelectrode distance, $2 \mathrm{~cm}$ ). The amplified EMG signals were filtered

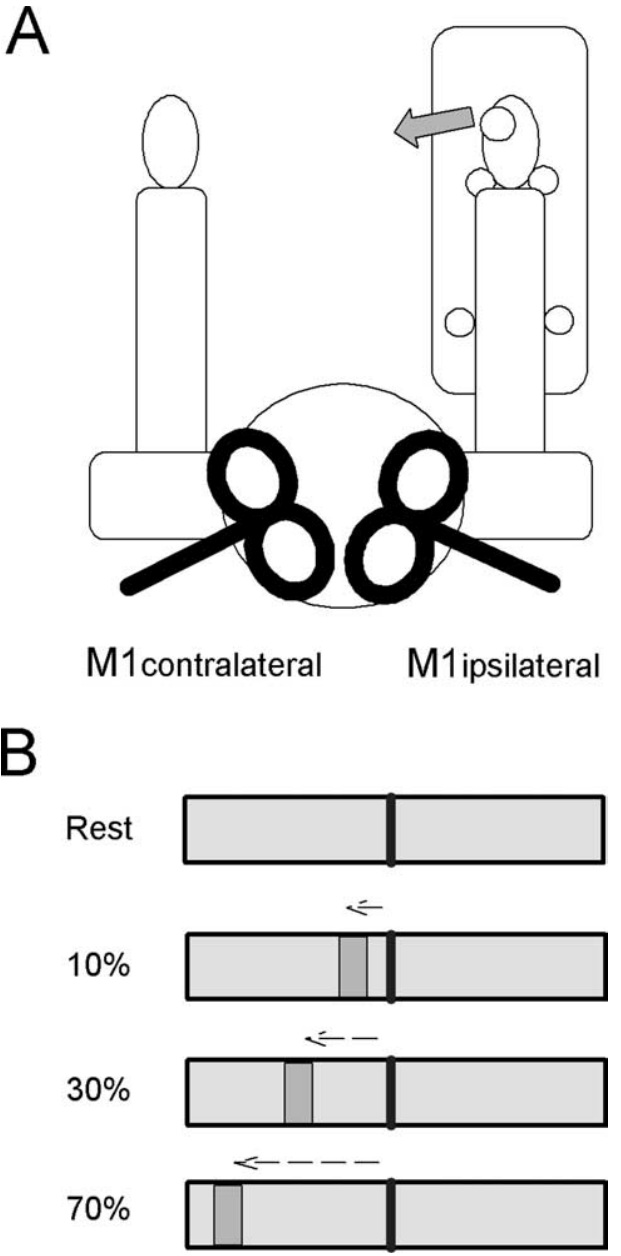

Figure 1. Experimental set-up. $\boldsymbol{A}$, Schematic of the experimental set-up. Subjects were instructed by the monitor to perform different levels of maximal right wrist flexion force while $\mathrm{RC}, \mathrm{SICl}, \mathrm{IHI}$, and the influence of IHI on SICI were tested in the left, resting hand. The right forearm was immobilized in the manipulandum. The figure also illustrates the position of the TMS coils. $\boldsymbol{B}$, Diagram showing the visual display presented to all subjects during testing. The black vertical line in the center is the cursor that subjects were instructed to move by performing right isometric wrist flexion force over the manipulandum. The " $\mathrm{G} 0$ " signal (dark gray box located to the left of the cursor) was also the target to where subjects had to move the cursor, maintaining it in position for 3-5 s. The distance between cursor and target related to the magnitude of force required to accomplish each task, normalized to the maximal wrist flexion force determined in each participant.

(bandpass, $25 \mathrm{~Hz}$ to $1 \mathrm{kHz}$ ), sampled at $2 \mathrm{kHz}$, and stored on a personal computer for off-line analysis.

TMS measurements. TMS was delivered to the optimal scalp position for activation of the FCR muscles overlying left- and right-hand primary motor cortices (hot spot). The hot spot shows good correlation with stimulation of Brodmann's area 4 (Mills et al., 1992). MEPs were elicited by transcranial magnetic stimuli delivered from a Magstim 200 stimulator (Magstim Company) through a figure-eight coil (loop diameter, 8 $\mathrm{cm}$; type number SP15560) with a monophasic current waveform. The coil was held tangential to the scalp with the handle pointing backward and $45^{\circ}$ away from the midline to activate the corticospinal system preferentially trans-synaptically via horizontal corticocortical connections (Di Lazzaro et al., 2004). Measures of motor cortical excitability included the resting motor threshold (RMT), MEP RCs, maximal MEP size (MEP$\max )$, SICI in the right $M 1_{\text {ipsilateral }}$ and IHI from $M 1_{\text {contralateral }}$ to $\mathrm{M}_{\text {ipsilateral }}$. Because of the length of the physiological measurements and to avoid excessive fatigue, all measurements were completed in three to four sessions. Four subjects were asked to return for an additional session to assess the effect of IHI on SICI at 70\% of maximal right wrist flexion force and at rest. 
MEPs RCs. RCs were measured in the left FCR while the right FCR was at rest and during 10,30, and $70 \%$ of maximal right wrist flexion force in all subjects. At all times, the left FCR remained at rest. Stimulus intensities started at $5 \%$ below the RMT, defined as the lowest intensity of TMS output required to evoke MEPs of at least $50 \mu \mathrm{V}$ in peak-to-peak amplitude in at least three of five consecutive trials (Rossini et al., 1994). Stimulus intensities were increased in $5 \%$ steps of maximal device output until the MEP amplitude did not show additional increases (MEP-max, defined in all participants). Five MEPs were recorded at each stimulation intensity, and each RC determination was repeated twice. Therefore, 10 trials were available to determine MEP amplitudes at each stimulus intensity. TMS pulses were given every $10 \mathrm{~s}$. Several periods of rest were given to subjects between trials to avoid muscle fatigue. MEP amplitudes were measured peak to peak, averaged off-line, and expressed as a percentage of the maximal peripheral motor response (M-max). To determine M-max, the median nerve was stimulated ( $1 \mathrm{~ms}$ rectangular pulse) with supramaximal intensity using bipolar surface electrodes placed at the elbow. Subsequently, data were normalized to the individual RMT of each participant.

SICI. SICI in $\mathrm{M1}_{\text {ipsilateral }}$ was measured in the left FCR while the right FCR was at rest and during 10,30, and 70\% of maximal right wrist flexion force in all subjects. At all times, the left FCR remained at rest. SICI was tested using the method described by Kujirai et al. (1993). A conditioning stimulus (CS) was set at an intensity of the RMT that elicited an amount of inhibition of $\sim 50 \%$ at rest. In all subjects, the intensity used for the CS ranged from 33 to $53 \%$ of the stimulator output $(45.3 \pm 6.1 \%$ of stimulator output) corresponding to $79.4 \%$ of the RMT. This low-intensity stimulus does not activate corticospinal fibers and does not produce changes in the excitability of spinal motoneurons (Di Lazzaro et al., 2001). The same stimulation intensity used for the CS at rest was used during trials in which 10,30 , and $70 \%$ of maximal right wrist flexion force was completed. The test stimulus (TS) was adjusted to produce an MEP of $\sim 0.3-0.5 \mathrm{mV}$ at rest. Test stimuli were delivered $2.5 \mathrm{~ms}$ after CS, an optimal interstimulus interval for eliciting SICI and to avoid mixture of the two phases of inhibition (Fisher et al., 2002). At this interval, SICI is prone to contamination by the second peak of short-interval intracortical facilitation (Ziemann et al., 1998), which may, to some extent, affect SICI. In cases in which TS size was facilitated by the right wrist flexion, the TS intensity was adjusted to match a size of $0.3-0.5 \mathrm{mV}$. Ten test stimuli and conditioning stimuli were presented randomly at each condition, and responses were recorded for off-line analysis. Stimuli were applied every $10 \mathrm{~s}$. Several periods of rest were given to subjects between trials to avoid muscle fatigue. Measurements were repeated three times at rest until a consistent baseline was established. After the baseline was established, two measurements were done at each level of right wrist flexion and averaged.

IHI. IHI from $\mathrm{M} 1_{\text {contralateral }}$ to $\mathrm{M}_{\text {ipsilateral }}$ was measured in the left FCR during 10, 30, and 70\% of maximal right wrist flexion force in all subjects. At all times, the left FCR remained at rest. IHI was tested after a randomized conditioning-test design reported previously (Ferbert et al., 1992). A suprathreshold CS was set at an intensity of the RMT that elicited an amount of inhibition of $\sim 50 \%$. In all subjects, the intensity used for the CS ranged from 58 to $76 \%$ of the stimulator output $(67.2 \pm$ $6 \%$ of stimulator output) corresponding to $122.8 \%$ of the RMT. The same stimulation intensity was used for the CS during 10,30 , and $70 \%$ of force. Testing was also completed, when the intensity of the CS was adjusted to maintain similar conditioned MEP (the "conditioned MEP" is the MEP elicited by the CS and TS) amplitudes during right wrist flexion force (Chen, 2004). Here, the size of the CS was maintained around $1 \mathrm{mV}$ during all levels of right wrist flexion $(10 \%=1.3 \pm 0.8 \mathrm{mV}$; $30 \%=1.4 \pm 1 \mathrm{mV} ; 70 \%=1.2 \pm 0.8 \mathrm{mV}$ ) by decreasing the intensity of the CS pulse. We were not able, in all subjects, to match this MEP amplitude for the conditioned MEP when IHI was tested at rest (even increasing the stimulator output to $100 \%$ ). Therefore, we completed a separate test to compare the magnitude of IHI with the right FCR at rest and during $10 \%$ of force with and without adjustments of the conditioned MEP amplitude.

During all testing, the CS was given $10 \mathrm{~ms}$ before a TS delivered to the contralateral side. The CS was always given to the left M1, and the TS was
Table 1. Stimulus conditions used to test the effect of IHI on SICI

\begin{tabular}{|c|c|c|c|}
\hline \multirow[b]{2}{*}{ Condition } & \multicolumn{3}{|c|}{ Stimulus intensity } \\
\hline & $\operatorname{csS} 10$ & CS2 & TS \\
\hline $1 \mathrm{~A}$ & & & $0.3 \mathrm{mV}$ \\
\hline $1 B$ & & $80 \%$ RMT & $0.3 \mathrm{mV}$ \\
\hline $1 C$ & $120 \%$ RMT & & $0.3 \mathrm{mV}$ \\
\hline $1 D$ & & & TS $0.3 \mathrm{mV}_{\text {CCS10 }}$ \\
\hline $1 \mathrm{E}$ & & $80 \%$ RMT & TS $0.3 \mathrm{mV}_{\text {CCS10 }}$ \\
\hline $1 F$ & $120 \%$ RMT & & TS $0.3 \mathrm{mV}_{\text {CCS } 10}$ \\
\hline $1 \mathrm{G}$ & $120 \%$ RMT & $80 \%$ RMT & TS $0.3 \mathrm{mV}_{\text {CCS10 }}$ \\
\hline
\end{tabular}

$\mathrm{CCS} 10$, $\mathrm{CS}$ applied over the left $\mathrm{M}_{\text {ipsilateral }}$ delivered $10 \mathrm{~ms}$ before the $\mathrm{TS}$ applied over the right $\mathrm{M} 1_{\text {contralateral }} \mathrm{for}$ testing IHI; CS2, CS delivered $2.5 \mathrm{~ms}$ before $\mathrm{TS}$ for testing of SICl; $T \mathrm{TS} 0.3 \mathrm{mV} \mathrm{CcS}_{\text {cS10 }}$, TS adjusted to produce $0.3 \mathrm{mV}$ MEP in the presence of a previous CCS10 pulse.

always given to the right M1. In all testing, the size of the TS was maintained at $\sim 0.3-0.5 \mathrm{mV}$ at rest and during all levels of right wrist flexion. The coil was positioned at the optimal location for activating the left and right FCR, respectively. The two coils were secured by straps and attached to a coil holder to ensure that the same area of the primary motor cortex was stimulated. The handle of the coils pointed backward and laterally $\sim 45^{\circ}$ to the midsagittal line. The order of the testing was randomized. Ten test stimuli and conditioning stimuli were averaged during off-line analysis. Stimuli were applied every $10 \mathrm{~s}$. Several periods of rest were given to subjects between trials to avoid muscle fatigue. Measurements were repeated three times at rest until a consistent baseline was established. After the baseline was established two measurements were done at each level of right wrist flexion and averaged.

Effect of IHI on SICI. Previous evidence demonstrated that SICI is reduced in the presence of IHI when tested at rest (Daskalakis et al., 2002). Here, we investigated whether SICI tested in the right $M 1_{\text {ipsilateral }}$ was altered by IHI from the left $\mathrm{M} 1_{\text {contralateral }}$ to the right $\mathrm{M} 1_{\text {ipsilateral }}$ at rest and during $70 \%$ of maximal right wrist flexion force using an experimental paradigm similar to that used before (Daskalakis et al., 2002). Because our results demonstrated that SICI decreased at $70 \%$ of force, we asked four subjects who had incomplete decrease in SICI at 70\% of force and in whom we were able to elicit reliable SICI by changing the CS intensity to return for an additional testing session. Seven conditions were tested and are listed in Table 1 as $1 \mathrm{~A}-1 \mathrm{G}$. Conditions $1 \mathrm{~A}$ to $1 \mathrm{C}$ were used to determine SICI $(1 \mathrm{~B} / 1 \mathrm{~A})$ and IHI $(1 \mathrm{C} / 1 \mathrm{~A})$ for a $0.3 \mathrm{mV}$ test MEP. Because IHI inhibits the test MEP and SICI tested in $\mathrm{M} 1_{\text {ipsilateral }}$ may be altered by an attenuated test MEP, for conditions $1 \mathrm{D}-1 \mathrm{G}$ the strength of the TS was adjusted to produce a $0.3 \mathrm{mV}$ test MEP in the presence of an earlier conditioning pulse to $\mathrm{M}_{\text {contralateral }}$ that occurred $10 \mathrm{~ms}$ before a TS (CCS10). Here, we refer to this TS a "TS $0.3 \mathrm{mV}_{\mathrm{CCS} 10 .}$." This adjustment allowed us to match MEP amplitudes to produce a similar degree of corticospinal activation with (1F) and without (1D) preceding a CCS10. We studied SICI in the presence of IHI using three pulses in condition $1 \mathrm{G}$. We measured SICI (1E/1D) and IHI (1F/1D) with the increased TS strength (TS $0.3 \mathrm{mV}_{\mathrm{CCS} 10}$ ). In this experiment, we compared SICI in the presence of IHI $(1 \mathrm{G} / 1 \mathrm{~F})$ to SICI in the absence of IHI matched for test MEP amplitude (1B/1A) and TS intensity (1E/1D).

Data analysis. In the initial analysis, normal distribution was tested by the Kolmogorov-Smirnov tests for each variable, and Mauchly's test of sphericity was followed by a repeated-measures ANOVA to determine the effect of TASK (rest and 10, 30, and 70\%) on left FCR EMG activity and to determine the effect of TASK (rest and 10, 30, and 70\%) and stimulus INTENSITY $(1.0,1.1,1.2,1.3,1.4,1.5,1.6,1.7,1.8$, and 1.9) on MEP RCs. We also tested the effect of TASK (rest and 10, 30, and 70\%) on SICI and MEP-max. During IHI testing, we assessed the effect of TASK $(10,30$, and $70 \%)$ on IHI and used a paired $t$ test to compare IHI measurements at rest and during $10 \%$ of force. Repeated-measures ANOVA was used to test the effect of IHI on SICI. A Bonferroni post hoc test was used for multiple comparisons. Significance was set at $p<0.05$. Variance is expressed as mean \pm SD. Pearson correlation analysis was used to test correlations as needed. 


\section{Results}

MEP RCs

Figure $2 \mathrm{~A}$ illustrates left FCR MEPs recorded in a single subject while the right FCR was at rest and during 10, 30, and 70\% of maximal right wrist flexion force. Repeated-measures ANOVA showed effect of TASK $(F=23.2 ; p \leq 0.001)$, INTENSITY $(F=43.2 ; p \leq 0.001)$, and their interaction TASK $\times$ INTENSITY $(F=1.7$; $p=0.02)$ on left FCR MEP RCs in all subjects (Fig. $2 \mathrm{~B}$ ). Post hoc testing showed a significant increase in RC amplitude at $70 \%(p \leq 0.001)$ and 30\% ( $p \leq 0.001)$ of force compared with rest. MEP RCs were significantly larger at $70 \%$ compared with $30 \%(p \leq 0.001)$ and $10 \%(p \leq 0.001)$ of force. MEPs RC were significantly larger at $30 \%$ compared with $10 \%$ ( $p \leq 0.01)$. No differences were observed between MEPs $\mathrm{RC}$ at rest and during $10 \%(p=0.2)$ of force. RMTs remained unchanged across conditions $(F=1.56 ; p=0.2)$. Repeatedmeasures ANOVA showed effect of TASK $(F=8.9 ; p \leq 0.001)$ on MEP-max. Post hoc testing showed a significant increase in MEP-max at $70 \%$ (11.8 $\pm 6.6 \%$ of M-max; $p \leq 0.001)$ compared with rest $(6.7 \pm 3 \%$ of M-max; $p \leq 0.001)$ and $10 \%(7.2 \pm$ $2.9 \%$ of M-max; $p \leq 0.01)$ of force. No difference was observed between MEP$\max$ at rest and 10\% $(p=0.9)$ and $30 \%$ $(p=0.2)$ of force. MEP-max were larger at $70 \%$ compared with $30 \%$ ( $p=0.03$ ). EMG activity in the right FCR increased with increasing levels of right wrist flexion $(F=$ $7.2 ; p \leq 0.01$ ), while no changes were observed in EMG activity in the left FCR ( $F=$ $0.2 ; p=0.8$ ). In summary, left FCR MEPs $\mathrm{RC}$ amplitude increased with increasing levels of force generated by the right-hand.

\section{SICI}

Figure 3A illustrates changes in SICI in $M 1_{\text {ipsilateral }}$ recorded in a single subject while the right FCR was at rest and during 10,30 and $70 \%$ of force. Repeatedmeasures ANOVA showed a significant effect of TASK (rest and 10\%, 30\% and $70 \% ; F=20.03 ; p \leq 0.001$ ) (Fig. $3 B$ ) on SICI. Post hoc analysis revealed a significant attenuation of SICI (Cond. $\left.\mathrm{MEP}^{\star} 100\right) /$ Test MEP) at $70 \%$ (89.6 \pm $24.6 \% ; p \leq 0.001)$ and $30 \%(62.2 \pm$ $23.8 \% ; p=0.04)$ compared with rest $(42.7 \pm 9.2 \%)$. SICI was decreased at $70 \%$ compared with $30 \%(p \leq 0.001)$ and $10 \%$ ( $p \leq 0.01)$ of force. SICI was decreased, although not significantly, at 30\% compared with $10 \%$ ( $p=0.08$ ) of force. No difference was observed between SICI at rest and $10 \%$ (mean, $44.8 \pm 11.1 \% ; p=0.9$ ). Test MEP amplitudes across conditions were comparable (rest $=0.34 \pm 0.2 \mathrm{mV} ; 10 \%=$

A
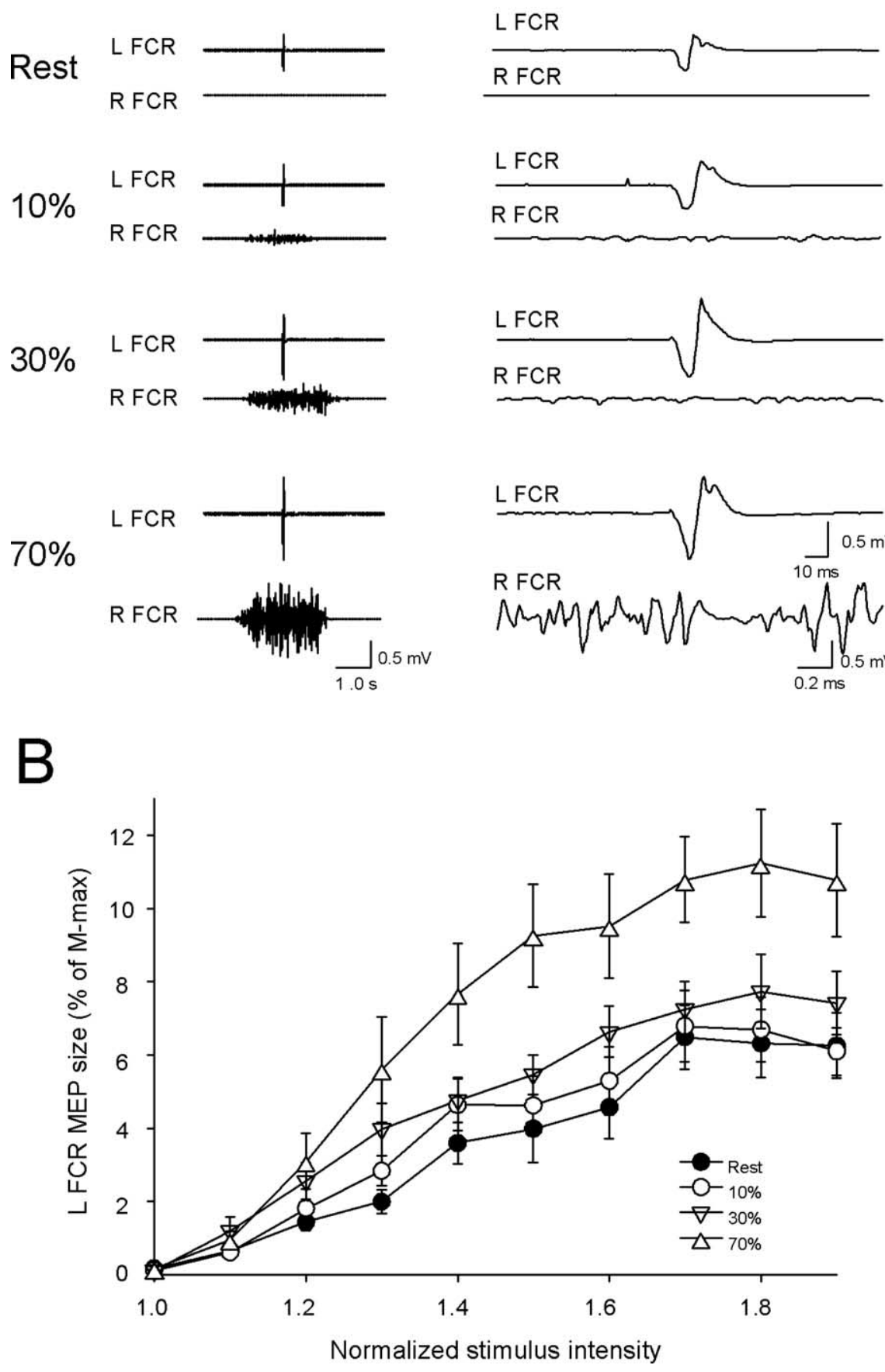

Figure 2. Recruitment curves. $\boldsymbol{A}, \mathrm{MEP}$ recorded from the left FCR of a representative subject during performance of different levels of maximal right wrist flexion force (rest and 10,30, and 70\%). In the left column, traces show burst of EMG activity across the different force levels, whereas in the right column, traces shows $1 \mathrm{~s}$ of EMG activity within each burst. Calibration bars are shown for the left FCR at rest and the right FCR across force levels. Note the increasing levels of EMG activity in the right $F C R$ (RFCR) while the left FCR (LFCR) remains at rest. $\boldsymbol{B}$, Group data $(n=10)$ showing left FCR MEP RCs at rest and during 10,30 , and $70 \%$ of maximal right wrist flexion force. The abscissa shows transcranial magnetic stimulus intensity expressed relative to the RMTs in each subject, and the ordinate shows MEP amplitudes as a percentage of the left FCR M-max. Error bars indicate SEs. ${ }^{*} p<0.05$. Note the progressive increment in RCs with increasing levels of maximal right wrist flexion force.
$0.3 \pm 0.15 \mathrm{mV} ; 30 \%=0.32 \pm 0.14 \mathrm{mV} ; 70 \%=0.35 \pm 0.22$ $\mathrm{mV} ; F=0.68 ; p=0.57)$. EMG activity in the right FCR increased with increasing levels of right wrist flexion $(F=8.1$; $p \leq 0.01)$, with no changes in EMG activity in the left FCR $(F=0.9 ; p=0.5)$. In summary, SICI tested in $\mathrm{M} 1_{\text {ipsilateral }}$ 


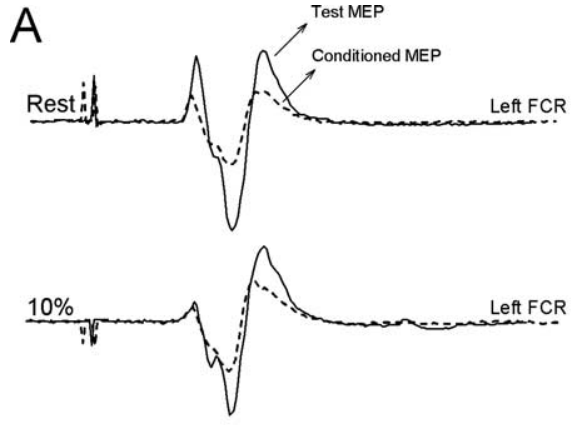

B
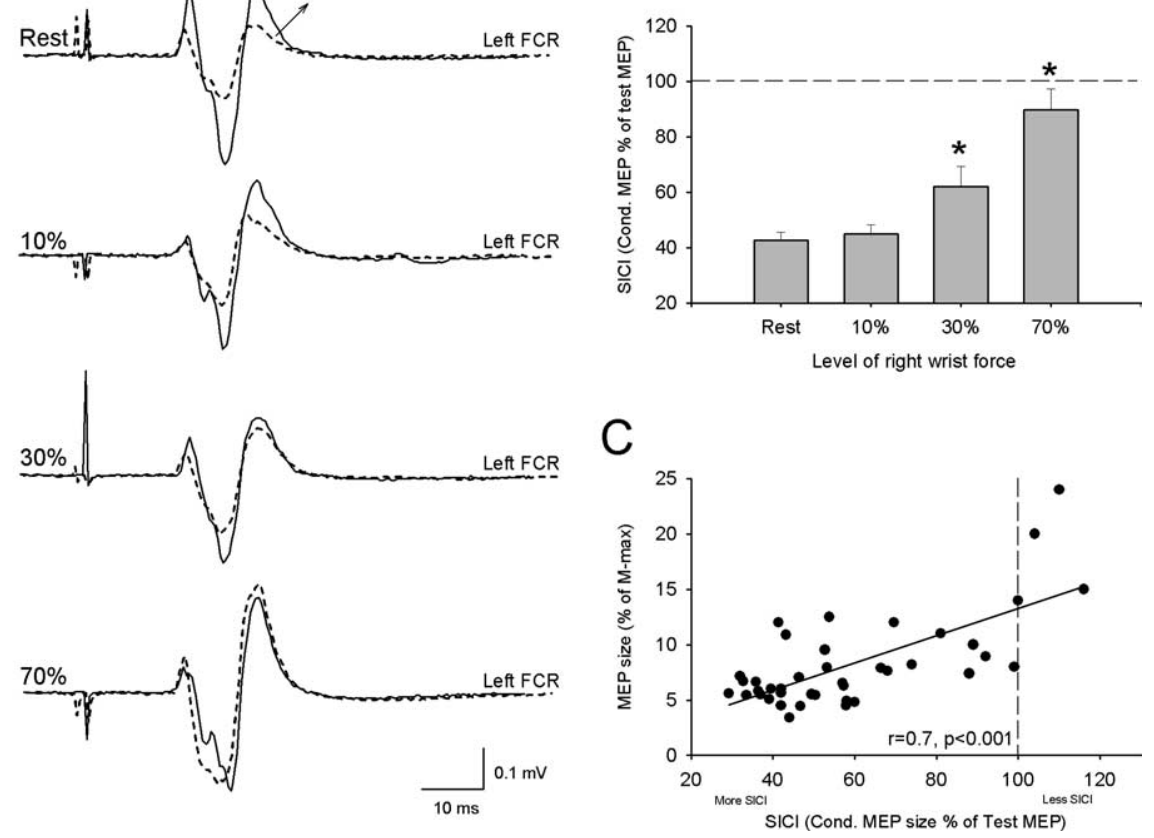

Figure 3. $\mathrm{SICl}$ in $\mathrm{M1}_{\text {ipsilateral }} \cdot \boldsymbol{A}, \mathrm{SICl}$ from the left $\mathrm{FCR}$ of a representative subject during performance of different levels of maximal right wrist flexion force (rest and 10,30, and 70\%). Solid lines, Test MEPs; dashed lines, conditioned MEPs. Note the well defined $\mathrm{SICl}$ at rest and $10 \%$ of maximal right wrist flexion force and the progressive disinhibition shown at 30 and $70 \%$ of maximal right wrist flexion force. $\boldsymbol{B}$, Group data $(n=10)$. The abscissa shows all conditions tested (rest and 10,30 , and $70 \%)$. The ordinate indicates the magnitude of $\mathrm{SICl}$ in $\mathrm{M}_{\text {ipsilateral }}$. The size of the conditioned MEP is expressed as a percentage of the size of test MEP amplitude (horizontal dotted line). Note the progressive attenuation in $\mathrm{SICl}$ at 30 and $70 \%$ of maximal right wrist flexion force. C, Relationship between SICI in $\mathrm{M}_{\text {ipsilateral }}$ (abscissa, vertical dotted line shows complete absence of SICI) and left FCR MEP-max (ordinate) at all conditions tested. Note that subjects that showed less SICl are those that showed larger left FCR MEP-max. Error bars indicate SEs. ${ }^{*} p<0.05$. Cond. MEP, Conditioned MEP.

decreased with increasing levels of force generated by the right hand.

\section{IHI}

With matched conditioned and test MEP amplitudes across force levels, Figure $4 A$ illustrates changes in IHI from $\mathrm{M} 1_{\text {contralateral }}$ to $\mathrm{M} 1_{\text {ipsilateral }}$ recorded in a single subject during 10,30 , and $70 \%$ of force. Repeated-measures ANOVA showed a significant effect of TASK $(10,30$, and 70\%; $F=9.5 ; p \leq 0.01$ ) (Fig. $4 B$ ) on IHI. Post hoc analysis revealed a significant attenuation of IHI (conditioned MEP $\times 100) /$ test MEP $)$ at $70 \%(82.7 \pm 26 \%)$ compared with $10 \%(48 \pm 10 \% ; p \leq 0.001)$ of force. IHI was decreased at $30 \%(71.7 \pm 22.8 \%$; $p=0.04)$ compared with $10 \%(p=0.02)$, but no differences were observed between 70 and $30 \%(p=0.4)$. Test $(10 \%=0.35 \pm 0.2 \mathrm{mV} ; 30 \%=0.40 \pm 0.16 \mathrm{mV} ; 70 \%=$ $0.45 \pm 0.3 \mathrm{mV} ; F=1.38 ; p=0.27)$ and conditioned MEP amplitudes $(10 \%=1.3 \pm 0.8 \mathrm{mV} ; 30 \%=1.4 \pm 1 \mathrm{mV} ; 70 \%=1.2 \pm$ $0.8 \mathrm{mV} ; F=1.4 ; p=0.3$ ) were comparable across conditions. EMG activity in the right FCR increased with right wrist flexion force $(F=6.3 ; p \leq 0.01)$, and no changes were observed in left FCR EMG activity $(F=1.08 ; p=0.4)$. With matched conditioned and test MEP amplitudes in a different set of experiments, we compared IHI at rest and during $10 \%$ of force. Here, IHI (rest $=55 \pm 24 \% ; 10 \%=68 \pm 20.5 \% ; p=0.36$ ) was comparable while the test (rest $=0.35 \pm 0.21 \mathrm{mV} ; 10 \%=0.41 \pm 0.26 \mathrm{mV}$; $p=0.2$ ) and conditioned MEP (rest $=0.35 \pm 0.21 \mathrm{mV} ; 10 \%=$ $0.41 \pm 0.26 \mathrm{mV} ; p=0.2$ ) amplitudes were matched. EMG activity in the right FCR increased at $10 \%$ compared with rest $(p=$ $0.01)$ with no changes in EMG activity in the left FCR $(p=0.43)$.
Without adjusting for the size of the conditioned MEP amplitude, repeatedmeasures ANOVA showed a significant effect of TASK $(10,30$, and $70 \% ; F=12.8$; $p \leq 0.001$ ) on IHI. IHI (conditioned MEP $\times 100) /$ test MEP) was significantly increased (as seen by lower numbers) at $70 \%(31.3 \pm 21 \%)$ compared with $30 \%$ $(64 \pm 21.5 \% ; p \leq 0.001)$ and $10 \%(52 \pm$ $11.8 \% ; p=0.02)$ of force. Test MEP amplitudes were comparable $(10 \%=0.46 \pm$ $0.22 \mathrm{mV} ; 30 \%=0.48 \pm 0.2 \mathrm{mV} ; 70 \%=$ $0.53 \pm 0.32 \mathrm{mV} ; F=0.26 ; p=0.7)$, whereas the size of the conditioned MEP increased with increasing force $(10 \%=$ $1.0 \pm 0.6 \mathrm{mV} ; 30 \%=1.7 \pm 1 \mathrm{mV} ; 70 \%=$ $3.4 \pm 1.4 \mathrm{mV})$. EMG activity in the left FCR was comparable across conditions $(p=$ 0.51). Without adjusting for the size of the conditioned MEP amplitude, we also compared IHI at rest and during $10 \%$ of force in a different set of experiments. IHI (conditioned MEP $\times 100) /$ test MEP) increased at $10 \%$ (48 $\pm 17.7 \%)$ compared with rest (63.6 $\pm 22 \% ; p=0.04)$ when test MEP amplitudes were comparable (rest = $0.28 \pm 0.22 \mathrm{mV} ; 10 \%=0.29 \pm 0.19 \mathrm{mV}$; $p=0.55)$, and the size of the conditioned MEP increased at $10 \%(1.15 \pm 0.56 \mathrm{mV})$ compared with rest $(0.34 \pm 0.32 \mathrm{mV} ; p \leq$ $0.001)$. EMG activity in the right FCR increased at $10 \%$ compared with rest $(p=$ $0.01)$, whereas no changes were observed in EMG activity in the left FCR ( $p=0.73)$.

In summary, IHI from $\mathrm{M} 1_{\text {contralateral }}$ to $\mathrm{M} 1_{\text {ipsilateral }}$ decreases with increasing levels of force generated by the right hand when the size of the conditioned MEP is matched across conditions. However, IHI from $M 1_{\text {contralateral }}$ to $M 1_{\text {ipsilateral }}$ increases with increasing levels of force generated by the right hand when the size of the conditioned MEP is not adjusted between force levels.

\section{Correlation analysis}

When all conditions (rest and 10,30, and 70\%) were tested, we found a significant correlation between SICI in $\mathrm{M}_{\text {ipsilateral }}$ and left FCR MEP-max $(r=0.73 ; p \leq 0.001)$ (Fig. $3 C)$ and between SICI and force levels $(r=0.75 ; p \leq 0.001)$. Subjects who had larger MEP-max during right wrist flexion were also the ones with less SICI. The analysis of each separate condition revealed a significant correlation between MEP-max and SICI at 30\% ( $r=$ $0.68 ; p=0.03)$ and $70 \%(r=0.8 ; p \leq 0.001)$ of force. In contrast, we found no correlation between MEP-max and IHI when tested with $(r=-0.1 ; p=0.46)$ (Fig. $4 C)$ or without $(r=-0.06 ; p=$ 0.6 ) adjustments of the conditioned MEP amplitude. SICI and IHI were correlated only when IHI was tested by adjusting the conditioned MEP amplitude (Fig. 5) (70\%: $r=-0.68, p=0.01$; $30 \%: r=-0.52, p=0.12 ; 10 \%: r=0.14, p=0.69$; rest: $r=0.12$, $p=0.7)$.

\section{Effect of IHI on SICI}

Figure 6 illustrates the effect of IHI from $\mathrm{M} 1_{\text {contralateral }}$ to $\mathrm{M} 1_{\text {ipsilateral }}$ on SICI in $\mathrm{M}_{\text {ipsilateral }}$ at rest and during $70 \%$ of force. The experimental setting for this experiment is shown in Table 1. The MEP amplitude for TS $0.3 \mathrm{mV}$ was $0.26 \pm 0.17 \mathrm{mV}$ (Table 1 , 
condition 1A) and for TS $0.3 \mathrm{mV}_{\mathrm{CCS} 10}$ was $0.56 \pm 0.43 \mathrm{mV}$ (condition 1D). When a TS $0.3 \mathrm{mV}_{\mathrm{CCS} 10}$ was preceded by CCS10, the test MEP amplitude was $0.3 \pm 0.27 \mathrm{mV}$ (Table 1, condition 1F). Then, the test MEP amplitudes for conditions $1 \mathrm{~A}$ and $1 \mathrm{~F}$ were matched $(p=0.5)$ (Table 1$)$. Compared with a TS $0.3 \mathrm{mV}_{\mathrm{CCS} 10}$ (Table 1 , condition 1D), a preceding CS2 (Table 1, condition $1 \mathrm{E})$ or CCS10 (Table 1, condition $1 \mathrm{~F}$ ) inhibited the test response. The nature of the test MEP had a significant effect on SICI $(F=8.6 ; p=0.01)$. The post hoc test showed a significant reduction in SICI in the presence of IHI $(96 \pm 26 \%)$ (Table 1 , conditions $1 \mathrm{G} / 1 \mathrm{~F})$ compared with SICI alone $(52 \pm 14 \%$; $p=0.02$ ) (Table 1 , conditions 1B/1A; Fig. 6D) and to SICI when comparisons were made using the TS 0.3 $\mathrm{mV}_{\mathrm{CCS} 10}(46 \pm 5 \% ; p=0.03)$ (Table 1 , conditions 1E/1D; Fig. $6 D$ ) during $70 \%$ of force. In all subjects, we observed the disinhibitory effect of IHI on SICI. In the same subjects at rest (TS $0.3 \mathrm{mV}, 0.41 \pm 0.33$ $\mathrm{mV}$; TS $0.3 \mathrm{mV}_{\mathrm{CCS} 10}, 0.79 \pm 0.41 \mathrm{mV}$ ), the test MEP had a significant effect on SICI $(F=8.4 ; p=0.01)$. SICI was significantly reduced in the presence of IHI $(66.4 \pm$ $34 \%$ ) (Table 1 , conditions $1 \mathrm{G} / 1 \mathrm{~F}$ ) compared with SICI alone $(41 \pm 24 \% ; p=$ 0.04) (Table 1, conditions 1B/1A; Fig. 6C) and to SICI when comparisons were made using the TS $0.3 \mathrm{mV}_{\mathrm{CCS} 10}(36.3 \pm 23.7 \%$; $p=0.02$ ) (Table 1, conditions 1E/1D; Fig. $6 C)$. Our results show that the inhibition from SICI (conditions 1B/1A, $52 \pm 14 \%$; conditions 1E/1D, $46 \pm$ $5 \%$ ) and $\mathrm{IHI}$ (conditions $1 \mathrm{C} / 1 \mathrm{~A}, 58.7 \pm 10 \%$; conditions $1 \mathrm{~F} / 1 \mathrm{D}$, $51.6 \pm 7 \%$ ) do not add together, consistent with the idea that SICI is disinhibited by transcallosal input. In addition, the disinhibitory effect of IHI on SICI was significantly stronger at $70 \%$ of force compared with rest $(p=0.03)$. In summary, at rest and during $70 \%$ of force, IHI from $\mathrm{M} 1_{\text {contralateral }}$ to $\mathrm{M} 1_{\text {ipsilateral }}$ decreased SICI in $\mathrm{M} 1_{\text {ipsilateral }}$. However, the disinhibitory effect of IHI on SICI is stronger at 70\% of force compared with rest.

\section{Discussion}

In the present study, we investigated the neuronal mechanisms contributing to control the corticospinal output to a resting hand during performance of a contralateral unimanual force generation task. We found activity-dependent changes in (1) SICI in $\mathrm{M} 1_{\text {ipsilateral, }}$ which controls the resting hand, (2) IHI from $\mathrm{M} 1_{\text {contralateral }}$ to $\mathrm{M} 1_{\text {ipsilateral }}$, and (3) the influence of IHI over SICI in the left resting hand during performance of a parametric force generation task with the right hand.

Previous studies showed that performance of high levels of force with one hand results in an increase in corticomotor excitability targeting the contralateral resting hand (Hess et al., 1986; Meyer et al., 1995; Stedman et al., 1998; Tinazzi and Zanette, 1998; Muellbacher et al., 2000; Hortobagyi et al., 2003), whereas performance of low levels of force led to conflicting results: facilitation, inhibition, or no changes (Hess et al., 1986; Stedman et al., 1998; Liepert et al., 2001; Sohn et al., 2003). These results raised the untested hypothesis that the mechanisms within the

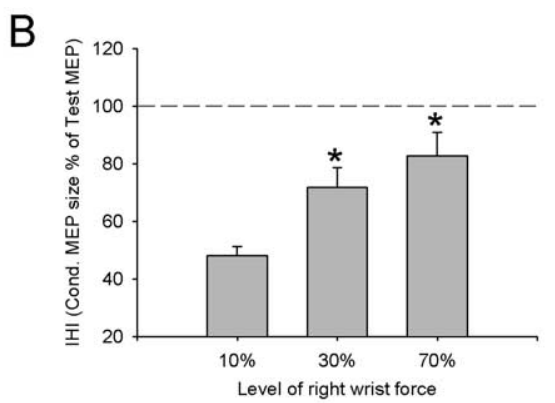

C

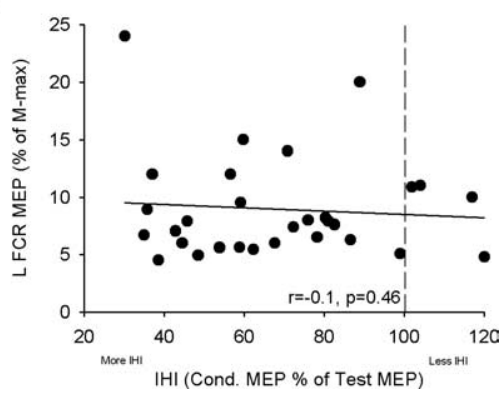

Figure 4. IHI from $M 1_{\text {contralateral }}$ to $M 1_{\text {ipsilateral }} \boldsymbol{A}, \mathrm{IHI}$ from $M 1_{\text {contralateral }}$ to $M 1_{\text {ipsilateral }}(10 \mathrm{~ms})$ recorded from the left FCR of a

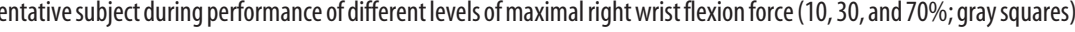
the MEP evoked by the (S (for eliciting IHI) and in light gray solid lines the raw EMG activity in the right FCR at the time of a prication of the TS alone. Note the well defined IHI at 10\% and the progressive disinhibition shown at 30 and $70 \%$ of maximal approaching the horizontal dotted line). C, Relationship between IHI from $\mathrm{M}_{\text {contralateral }}$ to $\mathrm{M}_{\text {ipsilateral }}$ and left FCRMEP-max at all three levels of maximal right wrist flexion force. Error bars indicate SEs. ${ }^{*} p<0.05$. Cond. MEP, Conditioned MEP.

primary motor cortex controlling corticospinal output to a resting hand may differ in an activity-dependent manner. To address this question, we evaluated various neurophysiological parameters including (1) RCs to TMS in $\mathrm{M1}_{\text {ipsilateral, }}$, which reflect excitability of high- and low-threshold motor cortical neurons to the stimulating magnetic coil (Siebner and Rothwell, 2003); (2) SICI in $M 1_{\text {ipsilateral }}$, which reflects activity in intracortical GABAergic inhibitory interneurons (Kujirai et al., 1993; Ziemann et al., 1996) shown to contribute to control the output from contralateral corticospinal neurons (Ziemann et al., 1996; Reynolds and Ashby, 1999; Buccolieri et al., 2004); (3) IHI from M1 $1_{\text {contralateral }}$ to $\mathrm{M} 1_{\text {ipsilateral }}$, mediated predominantly by transcallosal glutamatergic projections, acting through local GABAergic interneurons (Berlucchi, 1990; Ferbert et al., 1992; Meyer et al., 1995; Gerloff et al., 1998; Di Lazzaro et al., 1999; Chen, 2004); and (4) the influence of IHI over SICI (Daskalakis et al., 2002) controlling the resting hand with parametric changes in wrist force in the opposite hand.

\section{MEP RCs}

We found more prominent facilitation of MEPs elicited in the left resting FCR muscle at 30 and $70 \%$ of force than at rest and $10 \%$ of force when background EMG activity was comparable (see Results, MEP RCs). These findings are in agreement with previous studies demonstrating an increase in MEP size in a resting hand during higher levels of unimanual force generation by the opposite hand (Hess et al., 1986; Meyer et al., 1995; Stedman et al., 1998; Tinazzi and Zanette, 1998; Muellbacher et al., 2000; Hor- 


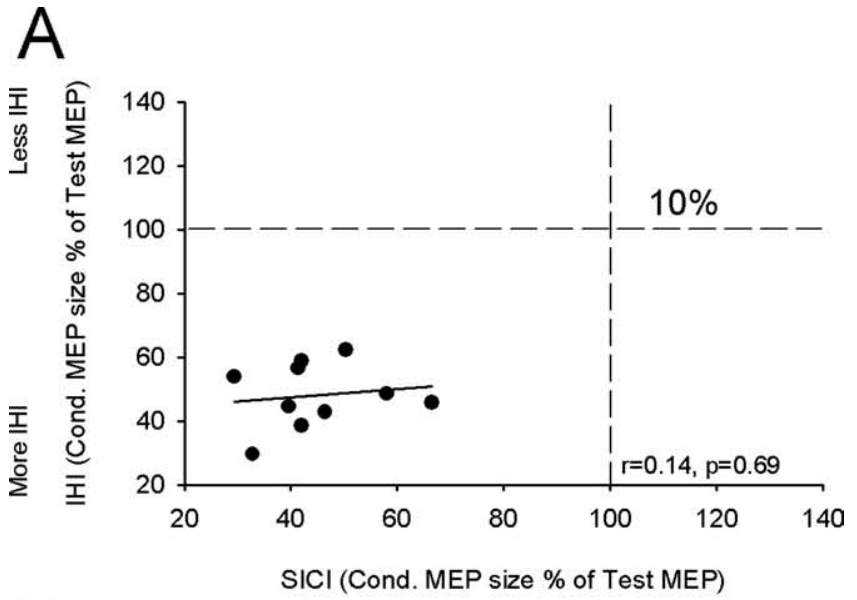

B
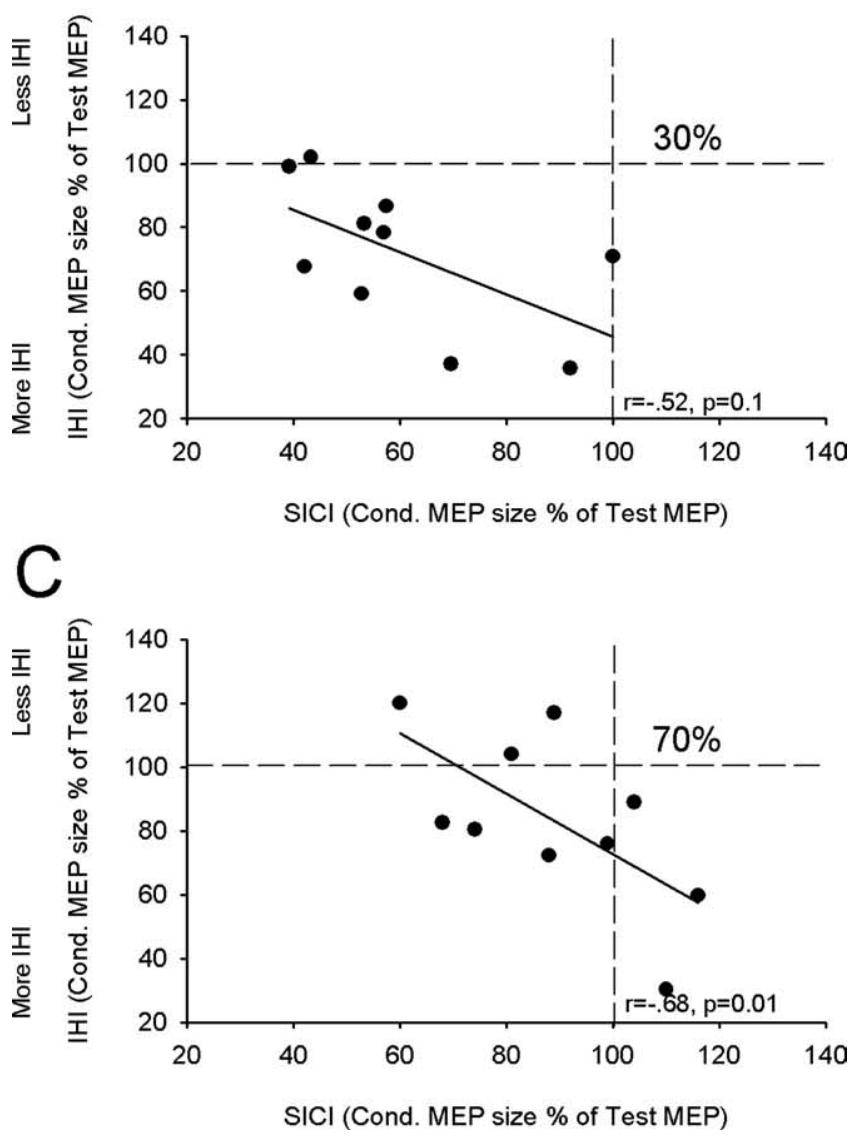

Figure 5. Relationship between IHI from $\mathrm{M1}_{\text {contralateral }}$ to $\mathrm{MI}_{\text {ipsilateral }}$ and $\mathrm{SICl}$ tested in $M 1_{\text {ipsilateral }}$ SICl in $\mathrm{M1}_{\text {ipsilateral }}$ and IHI from $\mathrm{M1}_{\text {contralateral }}$ to $\mathrm{M1}_{\text {ipsilateral }}$ at $10 \%(\boldsymbol{A}), 30 \%(\boldsymbol{B})$, and $70 \%$ (C) of right wrist flexion force. In all graphs, the ordinate shows the magnitude of IHI from $M 1_{\text {contralateral }}$ to $M 1_{\text {ipsilateral }}$ in which the size of the conditioned MEP (Cond. MEP) is expressed as a percentage of the size of test MEP amplitude. The abscissa shows the magnitude of SICI tested in $\mathrm{M}_{\text {ipsilateral }}$ in which the size of the conditioned MEP is expressed as a percentage of the size of test MEP amplitude. Note that at $70 \%$ of maximal right wrist flexion force the decrease in $\mathrm{SICl}$ is associated with an increase in IHI.

tobagyi et al., 2003). These results are also in agreement with Rau et al. (2003) demonstrating that during forceful phasic finger movements $M 1_{\text {ipsilateral }}$ is essentially facilitated.

\section{SICI}

We found that at 30 and $70 \%$ of right wrist force SICI tested in the left resting FCR was decreased compared with rest and to $10 \%$ of force. Although a previous study showed that maximal voluntary contraction of one hand decreased SICI in the other hand (Muellbacher et al., 2000), our results, to our knowledge, are the first reporting the influence of parametric increases in unimanual force generation on SICI in the M1 ipsilateral to the moving hand, referred to here as $M 1_{\text {ipsilateral }}$. We found that the magnitude of the exerted force correlated with the magnitude of changes in SICI. These results document activity-dependent modulation of SICI that might contribute to facilitate corticospinal excitability in $\mathrm{M1}_{\text {ipsilateral }}$ (Ziemann et al., 1996; Reynolds and Ashby, 1999; Buccolieri et al., 2004), a proposal consistent with the strong correlation that we found between the size of left FCR MEP-max and SICI across conditions (Fig. 3C). Given that the instruction to our subjects was to avoid contracting the left resting arm (see Materials and Methods), it would be theoretically possible that the reduction in SICI might be related to "volitional inhibition" (i.e., to the intent to suppress unwanted voluntary movements in the resting arm) (Waldvogel et al., 2000). However, such interpretation seems unlikely because volitional inhibition results in increases in SICI and suppression of corticospinal excitability, opposite to our results (Waldvogel et al., 2000; Sohn et al., 2002; Coxon et al., 2006).

IHI from $M 1_{\text {contralateral }}$ to $M 1_{\text {ipsilateral }}$

Our results also showed activity-dependent changes in IHI during performance of a force generation task by the opposite hand. Because in our experiment the conditioning transcranial magnetic stimulus was applied to the $\mathrm{M} 1_{\text {contralateral }}$ to the active hand, there are some considerations that need to be taken into account. The activity of intracortical circuits in $\mathrm{M}_{\text {contralateral }}$ changes with increasing levels of force (Zoghi and Nordstrom, 2007), and intracortical circuits influence IHI and corticospinal output originated from $M 1_{\text {contralateral }}$ (Lee et al., 2007). Therefore, we first tested IHI by matching the conditioned MEP amplitude to elicit the same level of corticospinal output across conditions (Chen, 2004). When the conditioned MEP amplitude was maintained constant, as required for IHI measurements (Chen, 2004), IHI at 30 and $70 \%$ force decreased compared with rest and to $10 \%$ force. Interestingly, the magnitude of left FCR MEP-max did not correlate with the changes in IHI, suggesting a less direct influence of IHI, compared with SICI, on MEP facilitation in $\mathrm{M} 1_{\text {ipsilateral }}$. When we did not correct for changes in CS MEP size, we found, as expected, that the same CS intensities resulted in much larger conditioned MEP amplitudes at higher levels of force. IHI tested in the left resting FCR increased at 10 and $70 \%$ of force, in agreement with previous results tested during mild voluntary contraction only (Ferbert et al., 1992; Hamzei et al., 2002; Talelli et al., 2008). More importantly and similar to the results when conditioned MEP amplitudes were corrected for, the magnitude of changes in the left FCR MEP-max also did not correlate with the magnitude of increases in IHI. Altogether, results using both techniques to measure IHI pointed clearly toward a less direct influence of IHI on MEP facilitation observed in $\mathrm{M} 1_{\text {ipsilateral }}$. It is critical to note that, on one hand, by adjusting the size of the conditioned MEP (accomplished by decreasing the CS intensity), we normalized IHI to the increase in corticospinal excitability caused by voluntary contraction. On the other hand, the IHI results without adjusting the CS intensity (which caused larger MEPs in the right FCR muscle, as expected) might be interpreted as a "true" reflection of how IHI originating in the contralateral M1 changed with different degrees of contraction. Overall, these results indicate that changes in the state of the motor cortex re- 
ceiving the CS should be carefully weighted in the interpretation of IHI results.

It should also be kept in mind that there are multiple interhemispheric effects that can be assessed by TMS at different stimulus intensities and time intervals (Reis et al., 2008). We designed and controlled this study to evaluate specifically IHI at an interstimulus interval and stimulus intensity accepted to elicit this particular effect (Ferbert et al., 1992; Chen et al., 2003). Changes in these parameters may elicit different effects such as interhemispheric facilitation (Hanajima et al., 2001) or might mediate IHI through other mechanisms (Chen et al., 2003), not tested under our experimental design.

\section{Interactions between IHI and SICI}

An important finding in our investigation was that, in the presence of IHI, SICI in $\mathrm{M} 1_{\text {ipsilateral }}$ decreased at $70 \%$ of force. A first conclusion from these findings is that the influence of IHI over SICI appears to operate in behaviorally relevant settings (performance of a unimanual force generation task) as it does at rest (Daskalakis et al., 2002) (Fig. 6). These results suggest that our findings of a decreased SICI in $\mathrm{M} 1_{\text {ipsilateral }}$ may be related to changes in IHI. This is supported by the stronger disinhibitory effect of IHI on SICI at 70\% of force compared with rest. Also, the inverse correlation between IHI-SICI at 70\% of force when we adjusted for the conditioned MEP amplitude (i.e., subjects with larger IHI were those who showed less SICI) suggest an activity-dependent link between both mechanisms. Although speculative, the strong disinhibitory effect of IHI on SICI during $70 \%$ of force may contribute to balance activity of corticospinal cells in $\mathrm{M}_{\text {ipsilateral }}$.

Our findings suggest that activity-dependent modulation of SICI, IHI, and their interactions contribute to control the corticospinal output to a resting hand during performance of a unimanual force generation task. This conclusion is in tune with the view that intracortical function associated with performance of unimanual motor tasks relies on an active and often discrete interaction between both M1s (Murase et al., 2004; Duque et al., 2005, 2007), although differences may be seen between movements of the dominant and nondominant hand (Liepert et al., 2001; Ziemann and Hallett, 2001; Vines et al., 2006; Duque et al., 2007). On one side, our results show that a strong unimanual movement provides extra excitation to the $\mathrm{M} 1_{\text {ipsilateral }}$ in the absence of involuntary EMG activity in the contralateral resting arm. A possibility is that functional changes in SICI, IHI, and their interactions may be seen as processes tuning the corticospinal motor output from $\mathrm{M}_{\text {ipsilateral }}$. In our setting, at $10 \%$ of force the overall net interhemispheric effect targeting $M 1_{\text {ipsilateral }}$ is more inhibitory and similar to rest, whereas at $70 \%$, there is an overall release of inhibition. This is consistent with findings showing that during a strong unimanual contraction it is more likely to have the presence of mirror EMG activity than during
REST

B $\quad 70 \%$ of force
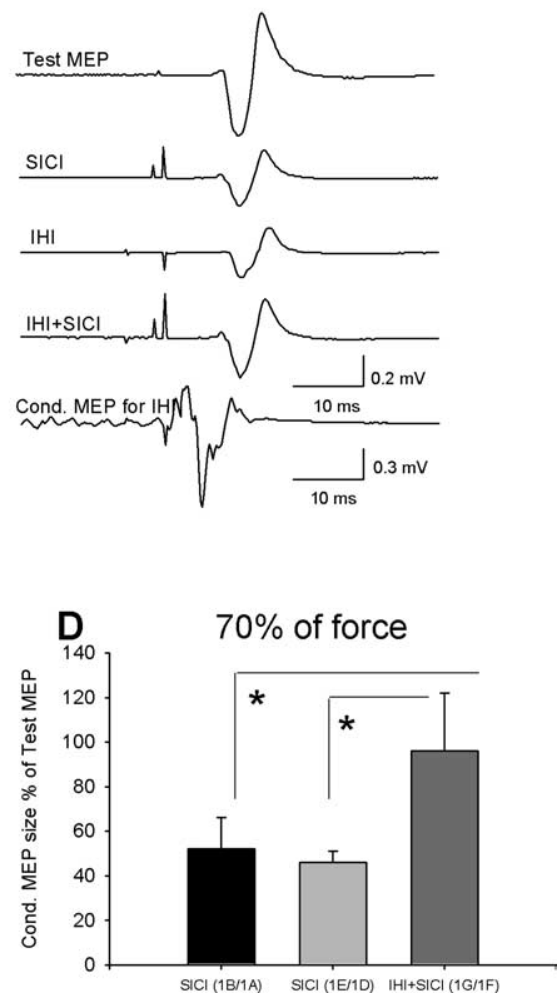

Figure 6. Effect of IHI from $M 1_{\text {contralateral }}$ to $M 1_{\text {ipsilateral }}$ on $\mathrm{SICl}$ tested in $\mathrm{M}_{\text {ipsilateral }}$ at rest and $70 \%$ of force. $\boldsymbol{A}, \boldsymbol{B}$, The first four traces (average of 10 single trials recorded from the left FCR) show test MEP amplitudes alone (Table 1, condition 1D), SICI tested in $\mathrm{M1}_{\text {ipsilateral }}$ alone (Table 1, condition $1 \mathrm{E}$ ), IHI from $\mathrm{M1}_{\text {contralateral }}$ to $\mathrm{M1}_{\text {ipsilateral }}$ alone (Table 1, condition 1F), and the effects of $\mathrm{SICl}$ in the presence of IHI (Table 1, conditions 1G/1F). The ordinate shows the size of the conditioned MEP expressed as a percentage of the size of test MEP. Error bars indicate SDs. ${ }^{*} p<0.05$.

small efforts (Zijdewind et al., 2006). In other unimanual tasks, the existence of disinhibition in the $\mathrm{M} 1_{\text {ipsilateral }}$ may vary depending on the behavioral context: distal versus proximal muscles involved (Harris-Love et al., 2007), level of complexity of the movement (Avanzino et al., 2008) and learning related improvements (Chen et al., 1997; Davare et al., 2007; Duque et al., 2007; Perez et al., 2007). On the other side, the activity-dependent changes in IHI-SICI identified here may provide insights to better understand unwanted mirror EMG activity in the opposite limb, which is frequently reported during unimanual movements in patients with motor disorders (Hashimoto et al., 2001; Georgiou-Karistianis et al., 2004; Cincotta and Ziemann, 2008). Although it has been widely considered that mirroring may relate to IHI (Carson, 2005; Daffertshofer et al., 2005; Duque et al., 2005, 2007; Li et al., 2007), our results suggest a more complex relationship in which mirroring might relate to interactions between circuits, such as IHI and SICI in the $\mathrm{M1}_{\text {ipsilateral }}$ rather than only to IHI. These results raise the importance of considering interactions between multiple circuits and not only the state of individual pathways when we search for the neural underpinnings of a behavioral phenomenon-like mirroring. Then, it is theoretically possible that activity-dependent abnormalities in IHI-SICI interactions may influence behavioral deficits reported 
in the "unaffected" limb after brain lesions such as stroke (Winstein and Pohl, 1995; Desrosiers et al., 1996; Yarosh et al., 2004; Murase et al., 2004; Ward and Cohen, 2004), an issue for future investigation. Finally, another possible functional role of these activity-dependent changes is that they operate when there is a need to control extended and bilateral overflow of high levels of motor activity, as during $70 \%$ of force. If so, IHI-SICI interactions targeting the $\mathrm{M} 1_{\text {ipsilateral }}$ to a hand engaged in unimanual force generation may vary according to the need to control corticospinal output to a resting hand in different behavioral sets.

\section{References}

Ashe J (1997) Force and the motor cortex. Behav Brain Res 87:255-269.

Avanzino L, Teo JT, Rothwell JC (2007) Intracortical circuits modulate transcallosal inhibition in humans. J Physiol (Lond) 583:99-114.

Avanzino L, Bove M, Trompetto C, Tacchino A, Ogliastro C, Abbruzzese G (2008) $1-\mathrm{Hz}$ repetitive TMS over ipsilateral motor cortex influences the performance of sequential finger movements of different complexity. Eur J Neurosci 27:1285-1291.

Berlucchi G (1990) Commisurotomy studies in animals. In: Handbook of neurophysiology, Vol 4 (Boller F, Grafman J, eds), pp 9-47. Amsterdam: Elsevier.

Buccolieri A, Abbruzzese G, Rothwell JC (2004) Relaxation from a voluntary contraction is preceded by increased excitability of motor cortical inhibitory circuits. J Physiol (Lond) 558:685-695.

Carson RG (2005) Neural pathways mediating bilateral interactions between the upper limbs. Brain Res Brain Res Rev 49:641-662.

Chen R (2004) Interactions between inhibitory and excitatory circuits in the human motor cortex. Exp Brain Res 154:1-10.

Chen R, Gerloff C, Hallett M, Cohen LG (1997) Involvement of the ipsilateral motor cortex in finger movements of different complexities. Ann Neurol 41:247-254.

Chen R, Yung D, Li JY (2003) Organization of ipsilateral excitatory and inhibitory pathways in the human motor cortex. J Neurophysiol 89:1256-1264.

Cincotta M, Ziemann U (2008) Neurophysiology of unimanual motor control and mirror movements. Clin Neurophysiol 119:744-762.

Cisek P, Crammond DJ, Kalaska JF (2003) Neural activity in primary motor and dorsal premotor cortex in reaching tasks with the contralateral versus ipsilateral arm. J Neurophysiol 89:922-942.

Coxon JP, Stinear CM, Byblow WD (2006) Intracortical inhibition during volitional inhibition of prepared action. J. Neurophysiol 95:3371-3383.

Daffertshofer A, Peper CE, Beek PJ (2005) Stabilization of bimanual coordination due to active interhemispheric inhibition: a dynamical account. Biol Cybern 92:101-109.

Dai TH, Liu JZ, Sahgal V, Brown RW, Yue GH (2001) Relationship between muscle output and functional MRI-measured brain activation. Exp Brain Res 140:290-300.

Daskalakis ZJ, Christensen BK, Fitzgerald PB, Roshan L, Chen R (2002) The mechanisms of interhemispheric inhibition in the human motor cortex. J Physiol (Lond) 543:317-326.

Davare M, Duque J, Vandermeeren Y, Thonnard JL, Olivier E (2007) Role of the ipsilateral primary motor cortex in controlling the timing of hand muscle recruitment. Cereb Cortex 17:353-362.

Desrosiers J, Bourbonnais D, Bravo G, Roy P-M, Guay M (1996) Performance of the "unaffected" upper extremity of elderly stroke patients. Stroke 27:1564-1570.

Dettmers C, Fink GR, Lemon RN, Stephan KM, Passingham RE, Silbersweig D, Holmes A, Ridding MC, Brooks DJ, Frackowiak RSJ (1995) Relation between cerebral activity and force in motor areas of the human brain. J Neurophysiol 74:802-815.

Di Lazzaro V, Oliviero A, Profice P, Insola A, Mazzone P, Tonali P, Rothwell JC (1999) Direct demonstration of interhemispheric inhibition of the human motor cortex produced by transcranial magnetic stimulation. Exp Brain Res 124:520-524.

Di Lazzaro V, Oliviero A, Profice P, Meglio M, Cioni B, Tonali P, Rothwell JC (2001) Descending spinal cord volleys evoked by transcranial magnetic and electrical stimulation of the motor cortex leg area in conscious humans. J Physiol (Lond) 537:1047-1058.

Di Lazzaro V, Oliviero A, Pilato F, Saturno E, Dileone M, Mazzone P, Insola A, Tonali PA, Rothwell JC (2004) The physiological basis of transcranial motor cortex stimulation in conscious humans. Clin Neurophysiol 115:255-266.

Duque J, Hummel F, Celnik P, Murase N, Mazzocchio R, Cohen LG (2005) Transcallosal inhibition in chronic subcortical stroke. NeuroImage 28:940-946.

Duque J, Mazzocchio R, Stefan K, Hummel F, Olivier E, Cohen LG (2007) Memory formation in the motor cortex ipsilateral to a training hand. Cereb Cortex, in press.

Evarts EV (1968) Relation of pyramidal tract activity to force exerted during voluntary movement. J Neurophysiol 31:14-27.

Ferbert A, Priori A, Rothwell JC, Day BL, Colebatch JG, Marsden CD (1992) Interhemispheric inhibition of the human motor cortex. J Physiol (Lond) 453:525-546.

Flament D, Goldsmith P, Buckley CJ, Lemon RN (1993) Task dependence of responses in first dorsal interosseous muscle to magnetic brain stimulation in man. J Physiol (Lond) 464:361-378.

Georgiou-Karistianis N, Hoy KE, Bradshaw JL, Farrow M, Chiu E, Churchyard A, Fitzgerald PB, Aramatas CA (2004) Motor overflow in Huntington's disease. J Neurol Neurosurg Psychiatry 75:904-906.

Gerloff C, Cohen LG, Floeter MK, Chen R, Corwell B, Hallett M (1998) Inhibitory influence of the ipsilateral motor cortex on responses to stimulation of the human cortex and pyramidal tract. J Physiol (Lond) 510:249-259.

Hamzei F, Dettmers C, Rzanny R, Liepert J, Büchel C, Weiller C (2002) Reduction of excitability ("inhibition") in the ipsilateral primary motor cortex is mirrored by fMRI signal decreases. NeuroImage 17:490-496.

Hanajima R, Ugawa Y, Machii K, Mochizuki H, Terao Y, Enomoto H, Furubayashi T, Shiio Y, Uesugi H, Kanazawa I (2001) Interhemispheric facilitation of the hand motor area in humans. J Physiol (Lond) 531:849-859.

Harris-Love ML, Perez MA, Chen R, Cohen LG (2007) Interhemispheric inhibition in distal and proximal arm representations in the primary motor cortex. J Neurophysiol 97:2511-2515.

Hasegawa Y, Kasai T, Tsuji T, Yahagi S (2001) Further insight into the taskdependent excitability of motor evoked potentials in first dorsal interosseous muscle in humans. Exp Brain Res 140:387-396.

Hashimoto T, Shindo M, Yanagisawa N (2001) Enhanced associated movements in the contralateral limbs elicited by brisk voluntary contraction in choreic disorders. Clin Neurophysiol 112:1612-1717.

Hess CW, Mills KR, Murray NM (1986) Magnetic stimulation of the human brain: facilitation of motor responses by voluntary contraction of ipsilateral and contralateral muscles with additional observations on an amputee. Neurosci Lett 71:235-240.

Hortobagyi T, Taylor JL, Petersen NT, Russell G, Gandevia SC (2003) Changes in segmental and motor cortical output with contralateral muscle contractions and altered sensory inputs in humans. J Neurophysiol 90:2451-2459.

Kujirai T, Caramia MD, Rothwell JC, Day BL, Thompson PD, Ferbert A, Wroe S, Asselman P, Marsden CD (1993) Corticocortical inhibition in human motor cortex. J Physiol (Lond) 471:501-519.

Lee H, Gunraj C, Chen R (2007) The effects of inhibitory and facilitatory intracortical circuits on interhemispheric inhibition in the human motor cortex. J Physiol (Lond) 580:1021-1032.

Lemon RN, Mantel GW, Muir RB (1986) Corticospinal facilitation of hand muscles during voluntary movement in the conscious monkey. J Physiol (Lond) 381:497-527.

Li JY, Espay AJ, Gunraj CA, Pal PK, Cunic DI, Lang AE, Chen R (2007) Interhemispheric and ipsilateral connections in Parkinson's disease: relation to mirror movements. Mov Disord 22:813-821.

Liepert J, Dettmers C, Terborg C, Weiller C (2001) Inhibition of ipsilateral motor cortex during phasic generation of low force. Clin Neurophysiol 112:114-121.

Maier MA, Bennett KM, Hepp-Reymond MC, Lemon RN (1993) Contribution of the monkey corticomotoneuronal system to the control of force in precision grip. J Neurophysiol 69:772-785.

Meyer BU, Roricht S, Grafin von Einsiedel H, Kruggel F, Weindl A (1995) Inhibitory and excitatory interhemispheric transfers between motor cortical areas in normal humans and patients with abnormalities of the corpus callosum. Brain 118:429-440.

Mills KR, Boniface SJ, Schubert M (1992) Magnetic brain stimulation with a double coil: the importance of coil orientation. Electroencephalogr Clin Neurophysiol 85:17-21. 
Muellbacher W, Facchini S, Boroojerdi B, Hallett M (2000) Changes in motor cortex excitability during ipsilateral hand muscle activation in humans. Clin Neurophysiol 111:344-349.

Murase N, Duque J, Mazzocchio R, Cohen LG (2004) Influence of interhemispheric interactions on motor function in chronic stroke. Ann Neurol 55:400-409.

Ni Z, Takahashi M, Yamashita T, Liang N, Tanaka Y, Tsuji T, Yahagi S, Kasai T (2006) Functional demanded excitability changes of human hand motor area. Exp Brain Res 170:141-148.

Perez MA, Wise SP, Willingham DT, Cohen LG (2007) Neurophysiological mechanisms involved in transfer of procedural knowledge. J Neurosci 27:1045-1053.

Rau C, Plewnia C, Hummel F, Gerloff C (2003) Event-related desynchronization and excitability of the ipsilateral motor cortex during simple selfpaced finger movements. Clin Neurophysiol 114:1819-1826.

Reis J, Swayne OB, Vandermeeren Y, Camus M, Dimyan MA, Harris-Love ML, Perez MA, Ragert P, Rothwell JC, Cohen LG (2008) Contribution of transcranial magnetic stimulation to the understanding of cortical mechanisms involved in motor control. J Physiol (Lond) 586:325-351.

Reynolds C, Ashby P (1999) Inhibition in the human motor cortex is reduced just before a voluntary contraction. Neurology 53:730-735.

Rossini PM, Barker AT, Berardelli A, Caramia MD, Caruso G, Cracco RQ, Dimitrijević MR, Hallett M, Katayama Y, Lücking $\mathrm{CH}$, Maertens de Noordhout AL, Marsden CD, Murray NMF, Rothwell JC, Swash M, Tomberg C (1994) Non-invasive electrical and magnetic stimulation of the brain, spinal cord and roots: basic principles and procedures for routine clinical application. Report of an IFCN committee. Electroencephalogr Clin Neurophysiol 91:79-92.

Rothwell JC, Colebatch J, Britton TC, Priori A, Thompson PD, Day BL, Marsden CD (1991) Physiological studies in a patient with mirror movements and agenesis of the corpus callosum. J Physiol (Lond) 438:34P.

Siebner HR, Rothwell J (2003) Transcranial magnetic stimulation: new insights into representational cortical plasticity. Exp Brain Res 148:1-16.

Sohn YH, Wiltz K, Hallett M (2002) Effect of volitional inhibition on cortical inhibitory mechanisms. J Neurophysiol 88:333-338.

Sohn YH, Jung HY, Kaelin-Lang A, Hallett M (2003) Excitability of the ipsilateral motor cortex during phasic voluntary hand movement. Exp Brain Res 148:176-185.

Stedman A, Davey NJ, Ellaway PH (1998) Facilitation of human first dorsal interosseous muscle responses to transcranial magnetic stimulation during voluntary contraction of the contralateral homonymous muscle. Muscle Nerve 21:1033-1039.

Talelli P, Waddingham W, Ewas A, Rothwell JC, Ward NS (2008) The effect of age on task-related modulation of interhemispheric balance. Exp Brain Res 186:59-66.

Tanji J, Okano K, Sato KC (1988) Neuronal activity in cortical motor areas related to ipsilateral, contralateral, and bilateral digit movements of the monkey. J Neurophysiol 60:325-343.

Thickbroom GW, Phillips BA, Morris I, Byrnes ML, Mastaglia FL (1998) Isometric force-related activity in sensorimotor cortex measured with functional MRI. Exp Brain Res 121:59-64.

Tinazzi M, Zanette G (1998) Modulation of ipsilateral motor cortex in man during unimanual finger movements of different complexities. Neurosci Lett 244:121-124.

van Duinen H, Renken R, Maurits NM, Zijdewind I (2008) Relation between muscle and brain activity during isometric contractions of the first dorsal interosseus muscle. Hum Brain Mapp 29:281-299.

Vines BW, Nair DG, Schlaug G (2006) Contralateral and ipsilateral motor effects after transcranial direct current stimulation. NeuroReport 17:671674

Waldvogel D, van Gelderen P, Muellbacher W, Ziemann U, Immisch I, Hallett M (2000) The relative metabolic demand of inhibition and excitation. Nature 406:995-998.

Ward NS, Cohen LG (2004) Mechanisms underlying recovery of motor function after stroke. Arch Neurol 61:1844-1848.

Winstein CJ, Pohl PS (1995) Effects of unilateral brain damage on the control of goal-directed hand movements. Exp Brain Res 105:163-174.

Yarosh CA, Hoffman DS, Strick PL (2004) Deficits in movements of the wrist ipsilateral to a stroke in hemiparetic subjects. J Neurophysiol 92:3276-3285.

Ziemann U, Hallett M (2001) Hemispheric asymmetry of ipsilateral motor cortex activation during unimanual motor tasks: further evidence for motor dominance. Clin Neurophysiol 112:107-113.

Ziemann U, Bruns D, Paulus W (1996) Enhancement of human motor cortex inhibition by the dopamine receptor agonist pergolide: evidence from transcranial magnetic stimulation. Neurosci Lett 208:187-190.

Ziemann U, Tergau F, Wassermann EM, Wischer S, Hildebrandt J, Paulus W (1998) Demonstration of facilitatory I wave interaction in the human motor cortex by paired transcranial magnetic stimulation. J Physiol (Lond) 511:181-190.

Zijdewind I, Butler JE, Gandevia SC, Taylor JL (2006) The origin of activity in the biceps brachii muscle during voluntary contractions of the contralateral elbow flexor muscles. Exp Brain Res 175:526-535.

Zoghi M, Nordstrom MA (2007) Progressive suppression of intracortical inhibition during graded isometric contraction of a hand muscle is not influenced by hand preference. Exp Brain Res 177:266-274. 